Check for updates

Cite this: RSC Adv., 2017, 7, 41962

Received 29th June 2017

Accepted 24th August 2017

DOI: $10.1039 / \mathrm{c} 7 \mathrm{ra0} 216 \mathrm{c}$

rsc.li/rsc-advances

\section{Bi-functional reduced graphene oxide/AgCo composite nanosheets: an efficient catalyst and SERS substrate for monitoring the catalytic reactions $\dagger$}

\begin{abstract}
Xiaowei Ma, Yue Guo, Jing Jin, Bing Zhao (iD) and Wei Song (DD *
The preparation of supported monodispersed bimetallic nanoparticles is important in the fields of catalysis and surface-enhanced Raman scattering (SERS) detection. In this work, a simple in situ co-reduction approach has been demonstrated for the synthesis of AgCo alloy nanoparticles with a size of 20$100 \mathrm{~nm}$ supported on the surface of reduced graphene oxide (rGO) nanosheets. The resulting $\mathrm{rGO} / \mathrm{AgCo}$ composite nanosheets are well characterized using scanning electron microscopy (SEM), transmission electron microscopy (TEM), Fourier transform infrared spectroscopy (FTIR), Raman spectroscopy, X-ray diffraction (XRD), and X-ray photoelectron microscopy (XPS) measurements. The as-prepared rGO/AgCo composite nanosheets show a superior catalytic activity for the reduction of methylene blue (MB) in the presence of $\mathrm{NaBH}_{4}$ and the degradation of $\mathrm{MB}$ under ultraviolet light over $\mathrm{rGO} / \mathrm{Ag}, \mathrm{rGO} / \mathrm{Co}, \mathrm{rGO} / \mathrm{Ag}_{3} \mathrm{Co}_{1}$ and $\mathrm{rGO} / \mathrm{Ag}_{1} \mathrm{CO}_{3}$ composite nanosheets. In addition, the $\mathrm{rGO} / \mathrm{AgCo}$ composite nanosheets have also been proved to be efficient surface-enhanced Raman scattering (SERS) substrates. The unique twodimensional structure and strong interactions between $\mathrm{rGO}$ and $\mathrm{AgCo}$ alloy nanoparticles contribute to the electromagnetic field SERS enhancement. Owing to the excellent catalytic properties and unique SERS sensitivity, a facile approach to monitor and determine the reaction kinetics of the catalytic reduction or photocatalytic degradation of $\mathrm{MB}$ using $\mathrm{rGO} / \mathrm{AgCo}$ composite nanosheets as both catalyst or photocatalyst and SERS substrate has been demonstrated. In addition, the as-prepared $\mathrm{rGO} / \mathrm{AgCo}$ composite nanosheets have also been used as efficient SERS substrates to monitor the plasmon-driven catalytic reaction of $p$-nitrothiophenol (PNTP) dimerizing into 4,4'-dimercaptoazobenzene (DMAB). Therefore, it is anticipated that this approach will be used to fabricate many other kinds of supported nanocatalysts, which could be applicable to study more general catalytic reaction processes and provide more information on the catalytic intermediates and final products.
\end{abstract}

\section{Introduction}

During the past decades, the fabrication of transition metal nanomaterials has attracted considerable interest due to their exceptional properties and broad applications in the fields of catalysis, electrocatalysis, electronics, chemical sensing, and biomedicine. ${ }^{1-5}$ Among the target materials, bimetallic nanomaterials have been especially interesting due to their synergistic enhanced properties. ${ }^{6}$ For example, Xia and co-workers reported the preparation of $\mathrm{Pd}-\mathrm{Pt}$ bimetallic nanodendrites toward the oxygen reduction reaction (ORR). ${ }^{7}$ It was found the Pd-Pt bimetallic nanodendrites showed five times more activity than the Pt-black catalyst. However, the naked bimetallic

State Key Laboratory of Supramolecular Structure and Materials, Jilin University, Changchun 130012, P. R. China. E-mail: weisong@jlu.edu.cn; Fax: +86-43185168473; Tel: +86-431-85168473

$\dagger$ Electronic supplementary information (ESI) available. See DOI: 10.1039/c7ra07216c nanoparticles with small size are usually easily aggregated due to their high surface energies, resulting in a decrease or loss of catalytic activity. Therefore, it is desirable to prepare bimetallic nanoparticles supported on some appropriate matrices such as carbon, molecular sieves, and polymers. ${ }^{8-10}$ For example, Jiang and co-workers synthesized bimetallic AgCo nanoparticles supported on loofah sponge carbon (LSC) for catalyzing the hydrolysis of $\mathrm{NaBH}_{4}$ toward hydrogen generation. ${ }^{8}$ It was found that the prepared LSC/AgCo composite with an appropriate ratio of $\mathrm{Ag}$ and Co showed a much higher catalytic activity than that of individual LSC/Ag and LSC/Co composites, demonstrating a synergistic effect between $\mathrm{Ag}$ and Co counterparts.

Graphene is an excellent support to deposit bimetallic nanomaterials due to their unique two-dimensional (2D) structure and large surface area, which offers them promising applications in catalysis, photocatalysis and electrocatalysis. ${ }^{\mathbf{1 1 - 1 3}}$ For example, Feng and co-workers prepared porous $\mathrm{Pt}-\mathrm{Au}$ nanodendrites supported on reduced graphene oxide (rGO) 
nanosheets for catalytic reduction of 4-nitrophenol by $\mathrm{NaBH}_{4}$, which exhibited an enhanced catalytic activity compared to Pt black and $\mathrm{Au}$ nanocrystals. ${ }^{\mathbf{1 4}}$ Kidwai and co-workers also demonstrated that AgNi alloy nanoparticles supported on rGO showed a superior catalytic activity over $\mathrm{rGO} / \mathrm{Ag}, \mathrm{rGO} / \mathrm{Ni}$ and individual AgNi nanoparticles toward the reduction of 4-nitrophenol in the presence of $\mathrm{NaBH}_{4} \cdot{ }^{15}$ Recently, rGO has also been reported to act as a support to immobilize Ag@CoNi nanoparticles, which displayed much higher catalytic activities toward the hydrolytic dehydrogenation of ammonia borane (AB) than the monometallic, bimetallic and individual Ag@CoNi counterparts. ${ }^{16}$

On the other hand, due to the unique 2D structure and excellent adsorption properties, graphene has been proved to be a good candidate as an efficient surface-enhanced Raman scattering (SERS) substrate. ${ }^{17,18}$ Recently, graphene supported metal nanoparticles have also been widely reported as SERS substrates with a high sensitivity. ${ }^{19-21}$ For instance, $\mathrm{Ag}$ or $\mathrm{Au}$ nanoparticles have been fabricated on the surface of reduced graphene oxide (rGO) nanosheets for SERS substrate to detect adsorbed aromatic molecules with a detection limit of only $10 \mathrm{nM}$. Recently, it has been attracted more and more attention for the fabrication of SERS-active substrates for the monitoring of the catalytic or photocatalytic reactions, which can provide some new insights into the reaction kinetics and mechanism. For example, Kang, Shao, and coworkers prepared $\mathrm{ZnO}-\mathrm{rGO}-\mathrm{Au}$ hybrid nanomaterials to be used as a both photocatalyst and SERS substrate, which can quantitatively monitor the catalytic degradation of Rhodamine 6G. ${ }^{22}$ Recently, we have demonstrated a facile approach for the fabrication of $\mathrm{Ag}-\mathrm{Cu}_{2} \mathrm{O} / \mathrm{rGO}$ nanocomposites, which can be employed as not only a peroxidase-like nanocatalyst but also good SERS substrate. ${ }^{23}$ On the basis of the high performance of bifunctional $\mathrm{Ag}-\mathrm{Cu}_{2} \mathrm{O} / \mathrm{rGO}$ nanocomposites, the detection of glucose with a high sensitivity and high selectivity has been achieved.

In this work, we have demonstrated a facile in situ coreduction approach for the preparation of AgCo alloy nanoparticles supported on the surface of rGO nanosheets. The asprepared $\mathrm{rGO} / \mathrm{AgCo}$ composite nanosheets are not only good catalysts for the reduction and photocatalysts for the degradation of methylene blue (MB), but also efficient SERS substrate due to the electromagnetic field contributions. More importantly, the as-prepared $\mathrm{rGO} / \mathrm{AgCo}$ composite nanosheets can be used to monitor and determine the reaction kinetics of the catalytic reduction and photocatalytic degradation of methylene blue (MB). In addition, the as-prepared $\mathrm{rGO} / \mathrm{AgCo}$ composite nanosheets has also been demonstrated to be used as SERS substrate to monitor of plasmon-driven catalytic reaction of $p$-nitrothiophenol (PNTP) dimerizing into 4,4'-dimercaptoazobenzene (DMAB). Our work provides a facile and general approach for the modification of metal alloy nanoparticles on the surface of rGO as bifunctional nanocatalyst and SERS substrate. Importantly, the hybrid nanostructures offer an opportunity for the monitoring of the catalytic and photocatalytic reaction process and determination of the reaction kinetics. This work will, therefore, be of great significance to study more general catalytic reaction processes and provide more information of the catalytic kinetics and mechanism.

\section{Experiment}

\subsection{Chemicals and materials}

Silver nitrate $\left(\mathrm{AgNO}_{3}\right)$ was purchased from Beijing Chemical Works. Cobalt nitrate $\left(\mathrm{Co}\left(\mathrm{NO}_{3}\right)_{2} \cdot 6 \mathrm{H}_{2} \mathrm{O}\right)$ was obtained from Xilong Chemical Co., Ltd. Natural graphite powder and sodium borohydride $\left(\mathrm{NaBH}_{4}\right)$ was bought from Sinopharm chemical reagent Beijing Co., Ltd. MB was purchased from Tianjin Guangfu Fine Chemical Research Institute. $p$-Aminothiophenol (PATP), 4-mercaptobenzoic acid (MBA) and PNTP was acquired from Sigma-Aldrich. All the chemicals were used as received without purification. Deionized water was used throughout the study.

\subsection{Synthesis of rGO/AgCo composite nanosheets}

First, GO was synthesized from natural graphite powder via a modified Hummer and Offeman method..$^{\mathbf{2 4} 25}$ Then, rGO/AgCo composite nanosheets were prepared via an in situ co-reduction approach. In a typical procedure, $40 \mathrm{mg}$ of GO was added into $30 \mathrm{~mL}$ of deionized water under sonication for about $1 \mathrm{~h}$, then a clear uniform GO aqueous solution was prepared. In the following, $0.2 \mathrm{mmol} \mathrm{Co}\left(\mathrm{NO}_{3}\right)_{2} \cdot 6 \mathrm{H}_{2} \mathrm{O}$ and $0.2 \mathrm{mmol} \mathrm{AgNO} \mathrm{N}_{3}$ were added into the above GO aqueous solution, then $12 \mathrm{~mL}$ of $\mathrm{NaBH}_{4}(1.0 \mathrm{M})$ was added. The $\mathrm{pH}$ value of the solution was about 9.0 at this time. After stirring for about $30 \mathrm{~min}$, the color of the solution changed from dark brown to black. After that, the above solution was transferred into a $50 \mathrm{~mL}$ round-bottom flask and heated at $110{ }^{\circ} \mathrm{C}$ under stirring for another $2.5 \mathrm{~h}$. After cooling down, the as-prepared product was collected by centrifuge and washed thoroughly with water and ethanol for several times. Finally, the prepared rGO/AgCo composite nanosheets were dried in air. The $\mathrm{rGO} / \mathrm{Ag}$ and $\mathrm{rGO} / \mathrm{Co}$ composite nanosheets with the same content of metal were also prepared via a similar procedure. The rGO/AgCo composite nanosheets with different $\mathrm{Ag} / \mathrm{Co}$ molar ratios were synthesized by varying the concentration of $\mathrm{AgNO}_{3}$ and $\mathrm{Co}\left(\mathrm{NO}_{3}\right)_{2} \cdot 6 \mathrm{H}_{2} \mathrm{O}$ in initial solution with the total molar amount of $(\mathrm{Ag}+\mathrm{Co})$ was kept constant. To find the influence of $\mathrm{pH}$ values of the solution for the reduction process, the $\mathrm{pH}$ values of solution were changed to 3 or 14 by adding a certain amount of $\mathrm{HNO}_{3}$ or $\mathrm{NaOH}$ after the addition of $\mathrm{NaBH}_{4}$.

\subsection{Catalytic reduction and photocatalytic degradation of MB}

In a typical procedure for the catalytic reduction of $\mathrm{MB}$ by $\mathrm{NaBH}_{4}, 30 \mu \mathrm{L}$ of MB solution $\left(10^{-3} \mathrm{M}\right)$ was added into $2.67 \mathrm{~mL}$ of water. Then $200 \mu \mathrm{L}$ of $\mathrm{rGO} / \mathrm{AgCo}$ composite nanosheets aqueous dispersions $\left(1 \mathrm{mg} \mathrm{mL}^{-1}\right)$ was added into the above solution. After that, $100 \mu \mathrm{L}$ of $\mathrm{NaBH}_{4}$ solution $\left(10^{-1} \mathrm{M}\right)$ was added into the above solution. For the photocatalytic degradation of MB under ultraviolet (UV) light, $30 \mu \mathrm{L}$ of MB solution $\left(10^{-3} \mathrm{M}\right)$ was added into $2.77 \mathrm{~mL}$ of water. Then $200 \mu \mathrm{L}$ of $\mathrm{rGO} /$ AgCo composite nanosheets aqueous dispersions $\left(1 \mathrm{mg} \mathrm{mL} \mathrm{m}^{-1}\right)$ 
was added into the above solution. After that, the above solution was illuminated under UV light. UV-vis spectral measurement was used to evaluate the catalytic and photocatalytic activities of the prepared $\mathrm{rGO} / \mathrm{AgCo}$ composite nanosheets.

\subsection{SERS measurements}

In a typical experiment, PATP and MBA were used as Raman probes to estimate the response of the $\mathrm{rGO} / \mathrm{AgCo}$ composite nanosheets substrate for SERS measurements. For the SERS detection of PATP, $180 \mu \mathrm{L}$ of PATP solution with different concentrations was mixed with $20 \mu \mathrm{L}$ of $\mathrm{rGO} / \mathrm{AgCo}$ composite nanosheets aqueous dispersions $\left(1 \mathrm{mg} \mathrm{mL}^{-1}\right)$. After standing for about $2 \mathrm{~h}, 60 \mu \mathrm{L}$ of the above solution was transferred for Raman measurements. The similar procedure was performed for the SERS detection of MBA under continuous $633 \mathrm{~nm}$ laser excitation.

\subsection{SERS monitoring of the catalytic reduction and photocatalytic degradation of $\mathrm{MB}$}

In a typical procedure for the SERS monitoring of the catalytic reduction of $\mathrm{MB}$ by $\mathrm{NaBH}_{4}, 30 \mu \mathrm{L}$ of $\mathrm{MB}$ aqueous solution $\left(10^{-3}\right.$ $\mathrm{M})$ was diluted to $2 \mathrm{~mL}$, then $180 \mu \mathrm{L}$ of the diluted $\mathrm{MB}$ aqueous solution was mixed with $20 \mu \mathrm{L}$ of $\mathrm{rGO} / \mathrm{AgCo}$ composite nanosheets aqueous dispersions $\left(1 \mathrm{mg} \mathrm{mL}^{-1}\right)$. After that, $20 \mu \mathrm{L}$ of $\mathrm{NaBH}_{4}$ solution $\left(10^{-2} \mathrm{M}\right)$ was added into $40 \mu \mathrm{L}$ of the above solution. The catalytic reduction process was measured by monitoring the SERS spectra of the final product at different reaction time. For the SERS monitoring of the photocatalytic degradation of $\mathrm{MB}$ under UV light, $30 \mu \mathrm{L}$ of $\mathrm{MB}$ aqueous solution $\left(10^{-3} \mathrm{M}\right)$ was diluted to $2 \mathrm{~mL}$, then $180 \mu \mathrm{L}$ of the diluted $\mathrm{MB}$ aqueous solution was mixed with $20 \mu \mathrm{L}$ of $\mathrm{rGO} / \mathrm{AgCo}$ composite nanosheets aqueous dispersions $\left(1 \mathrm{mg} \mathrm{mL}^{-1}\right)$. After that, the above solution was performed under UV light. SERS measurement was performed at different reaction time under continuous $532 \mathrm{~nm}$ laser excitation.

\subsection{SERS in situ monitoring of plasmon-enhanced driven catalytic reaction of PNTP dimerizing into DMAB}

In a typical experiment, PNTP ethanol solution $\left(10^{-3} \mathrm{M}\right)$ was diluted with water to prepare PNTP solution with a concentration of $10^{-5} \mathrm{M}$. Then $45 \mu \mathrm{L}$ of the PNTP aqueous solution was mixed with $5 \mu \mathrm{L}$ of $\mathrm{rGO} / \mathrm{AgCo}$ composite nanosheets aqueous dispersions (1 $\mathrm{mg} \mathrm{mL} \mathrm{mL}^{-1}$ ) for $30 \mathrm{~min}$ to ensure sufficient adsorption. After that, time-dependent SERS spectra of the plasmon-driven catalytic reaction were acquired directly from the above solution under continuous $532 \mathrm{~nm}$ laser excitation.

\subsection{Characterization}

The morphology of the rGO/AgCo composite nanosheets was operated on a scanning electron microscopy (SEM, Nova NanoSEM 450) and transmission electron microscopy (TEM, JEOL JEM-1200 EX) operated at 15 and $100 \mathrm{kV}$, respectively. High-resolution TEM (HRTEM) images and energy dispersive X-ray (EDX) analysis were performed on a JEOL JEM-2100F TEM operated at $200 \mathrm{kV}$. X-ray diffractometer (XRD, Empyrean
PANalytical B.V.) with $\mathrm{Cu}-\mathrm{K} \alpha$ radiation was used to measure the crystal structure of the samples. Raman spectra were characterized by Raman spectrometer (Renishaw-1000 spectrometer (He/Ne laser $532 \mathrm{~nm}$ ) and LabRAM ARAMIS Smart Raman Spectrometer (air-cooled He/Ne laser $633 \mathrm{~nm}$ )). The chemical composition of the synthesized $\mathrm{rGO} / \mathrm{AgCo}$ composite nanosheets was observed through X-ray photoelectron spectrometer (XPS, Thermo Scientific ESCALAB250). Ultraviolet-visible-near infrared (UV-VIS-NIR) spectra were performed on a SHIMADZU UV-3600 UV-Via-NIR spectrophotometer. Fourier transform infrared (FTIR) spectra were recorded on a BRUCKER VERTEX 80V FTIR Spectrometer.

\section{Results and discussion}

The rGO/AgCo composite nanosheets have been prepared via an in situ co-reduction approach. During the reaction process, the GO was reduced to $\mathrm{rGO}$ by $\mathrm{NaBH}_{4}$, and at the same time, AgCo nanoparticles were formed on the surface of rGO due to the same reduction process. Fig. 1a showed a typical SEM image of the as-prepared $\mathrm{rGO} / \mathrm{AgCo}$ composite nanosheets. It was clearly observed that the rGO/AgCo composite nanosheets possessed a 2D layer structure, and some of these nanosheets were wrinkled together. The TEM image showed that AgCo nanoparticles were well dispersed on the surface of rGO nanosheets (Fig. 1b). The size of AgCo nanoparticles was from 20 to $100 \mathrm{~nm}$. HRTEM image was further performed to reveal the crystalline structure of the as-prepared rGO/AgCo composite nanosheets, demonstrating high crystallinity of AgCo nanoparticles was calculated to be around $0.22 \mathrm{~nm}$, which is indexed to the (111) plane of face-centered cubic (fcc) of AgCo alloy nanocrystals (Fig. 1c). The as-prepared $\mathrm{rGO} / \mathrm{AgCo}$ composite nanosheets have also been characterized by energy-dispersive X-ray (EDX) spectroscopy (Fig. 1d), which displayed the existence of $\mathrm{C}, \mathrm{O}, \mathrm{Co}, \mathrm{Ag}, \mathrm{Cu}$, and $\mathrm{Si}$ elements in the spectrum. The $\mathrm{Cu}$ and $\mathrm{Si}$ elements originate from carbon coated copper grid and instrument. These results demonstrated the evidence of the successfully preparation of $\mathrm{rGO} / \mathrm{AgCo}$ composite nanosheets.
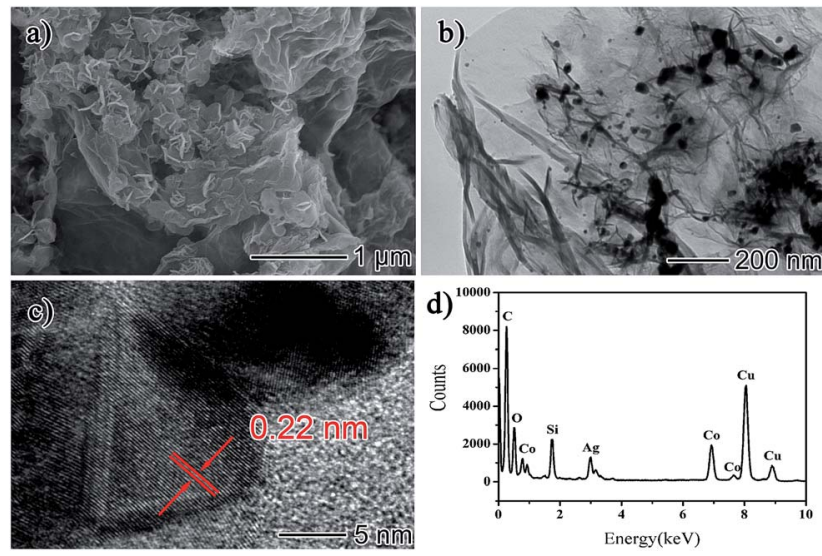

Fig. 1 (a) SEM and (b) TEM image of the rGO/CoAg composite nanosheets; (c) HRTEM image of the synthesized $\mathrm{rGO} / \mathrm{CoAg}$ composite nanosheets; (d) EDX images of the synthesized $\mathrm{rGO} / \mathrm{CoAg}$ composite nanosheets. 
FTIR and Raman spectra were also used to characterize the chemical structure of the as-prepared $\mathrm{rGO} / \mathrm{AgCo}$ composite nanosheets. Fig. 2a shows the FTIR spectra of GO and $\mathrm{rGO} / \mathrm{AgCo}$ composite nanosheets, respectively. It can be found the presence of numerous oxygen containing groups in the FTIR spectrum of GO product. For instance, the broad absorption band at $3394 \mathrm{~cm}^{-1}$ is ascribed to $\mathrm{O}-\mathrm{H}$ stretching vibration. The typical peaks at 1729,1395 and $1047 \mathrm{~cm}^{-1}$ are assigned to $\mathrm{C}-\mathrm{O}$ stretching mode, $\mathrm{O}-\mathrm{H}$ bending mode and $\mathrm{C}-\mathrm{O}$ stretching mode, respectively. The characteristic peak at $1625 \mathrm{~cm}^{-1}$ is related to the vibration of adsorbed water molecules on GO. After the modification of AgCo nanoparticles, the intensity of the absorption bands at 3394, 1729, 1395 and $1047 \mathrm{~cm}^{-1}$ decreased or disappeared, demonstrating that GO has been reduced up to a great extent. The appearance of the characteristic new absorption peak at $1564 \mathrm{~cm}^{-1}$ is ascribed to the skeletal vibration of rGO nanosheets. These results are in accordance with the previous reports. ${ }^{15,26}$ The chemical structure of the asprepared $\mathrm{rGO} / \mathrm{AgCo}$ composite nanosheets has also been revealed by Raman spectroscopy. As shown in Fig. 2b, two dominant $\mathrm{D}$ and $\mathrm{G}$ bands at 1345 and $1592 \mathrm{~cm}^{-1}$ were observed in all of the GO, $\mathrm{rGO} / \mathrm{AgCo}, \mathrm{rGO} / \mathrm{Ag}$ and $\mathrm{rGO} / \mathrm{Co}$ composite
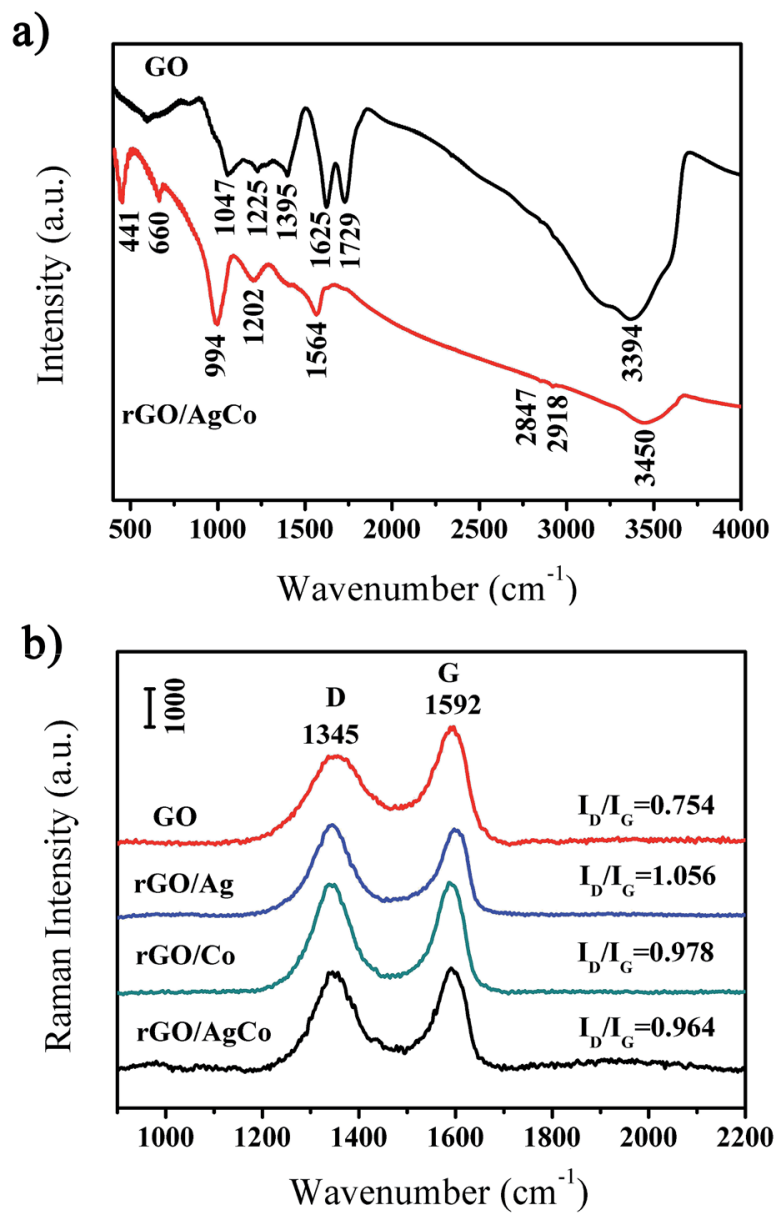

Fig. 2 (a) FTIR spectra of GO and $\mathrm{rGO} / \mathrm{AgCo}$ composite nanosheet samples; (b) Raman spectra of GO, rGO/Ag, $\mathrm{rGO} / \mathrm{Co}$ and $\mathrm{rGO} / \mathrm{AgCo}$ composite nanosheet samples. nanosheets. However, the intensity ratios between $\mathrm{D}$ and $\mathrm{G}$ band for $\mathrm{rGO} / \mathrm{AgCo}\left(I_{\mathrm{D}} / I_{\mathrm{G}}=0.964\right), \mathrm{rGO} / \mathrm{Ag}\left(I_{\mathrm{D}} / I_{\mathrm{G}}=1.056\right)$ and $\mathrm{rGO} /$ Co composite nanosheets $\left(I_{\mathrm{D}} / I_{\mathrm{G}}=0.978\right)$ are higher than that of individual GO $\left(I_{\mathrm{D}} / I_{\mathrm{G}}=0.754\right)$, suggesting the formation of a conjugated graphene network after the reduction of GO. ${ }^{27}$

The composition and phase purity of the as-prepared rGO/ AgCo composite nanosheets has been further examined by a XRD measurement. As shown in Fig. 3, the diffraction pattern of the rGO/AgCo composite nanosheets display five characteristic bands centered at $38.5,44.5,64.7,77.8$ and $81.9^{\circ}$, which showed a slight deviation from the (111), (200), (220), (311) and (222) planes of face centered cubic (fcc) structures of the Ag bulk state (JCPDS no. 04-0783). In addition, the (200) plane of rGO/ AgCo composite nanosheets lied between pure Ag (200) and pure $\mathrm{Ni}$ (111) peak, indicating the formation of AgCo alloy nanoparticles. As the redox potential of $\mathrm{Ag}^{+} / \mathrm{Ag}(0.8 \mathrm{~V})$ is much higher than that of $\mathrm{Co}^{2+} / \mathrm{Co}(-0.28 \mathrm{~V})$, therefore, the reduction rate of $\mathrm{Ag}^{+}$is higher than that of $\mathrm{Co}^{2+}$. In the presence of $\mathrm{NaBH}_{4}$, $\mathrm{Ag}$ is formed in the initial phase followed with sequential deposition of Co. The metallic Co atoms are stabilized by the Ag lattice, resulting in the formation of stable alloy nanoparticles. This result was similar with the previous report on the formation of AgNi alloy nanoparticles. ${ }^{15}$

XPS spectroscopy was used to characterize the chemical composition and valence state of the prepared $\mathrm{rGO} / \mathrm{AgCo}$ composite nanosheets. As shown in Fig. 4a, the survey spectrum clearly displayed $\mathrm{C}, \mathrm{O}, \mathrm{Ag}$ and Co elements in the $\mathrm{rGO} /$ AgCo composite nanosheets product. Fig. 4b represented the high resolution XPS spectrum of $\mathrm{C} 1 \mathrm{~s}$, which could be the high resolution XPS spectrum of $\mathrm{C} 1 \mathrm{~s}$, which could be deconvoluted into four peaks centered at 283.4, 284.7, 286.6 and $288.8 \mathrm{eV}$, which are ascribed to $\mathrm{C}-\mathrm{Co}, \mathrm{C}-\mathrm{C} / \mathrm{C}=\mathrm{C}, \mathrm{C}=\mathrm{O}$, and $\mathrm{O}=\mathrm{C}-\mathrm{O}$ bands of rGO, respectively. The high resolution XPS spectrum of Ag element exhibited two typical bands at 368.7 and $374.7 \mathrm{eV}$, which are attributed to the signals for $\mathrm{Ag} 3 \mathrm{~d}_{5 / 2}$ and $\mathrm{Ag} 3 \mathrm{~d}_{3 / 2}$, respectively, revealing the formation of metallic Ag (Fig. 4c). ${ }^{28}$

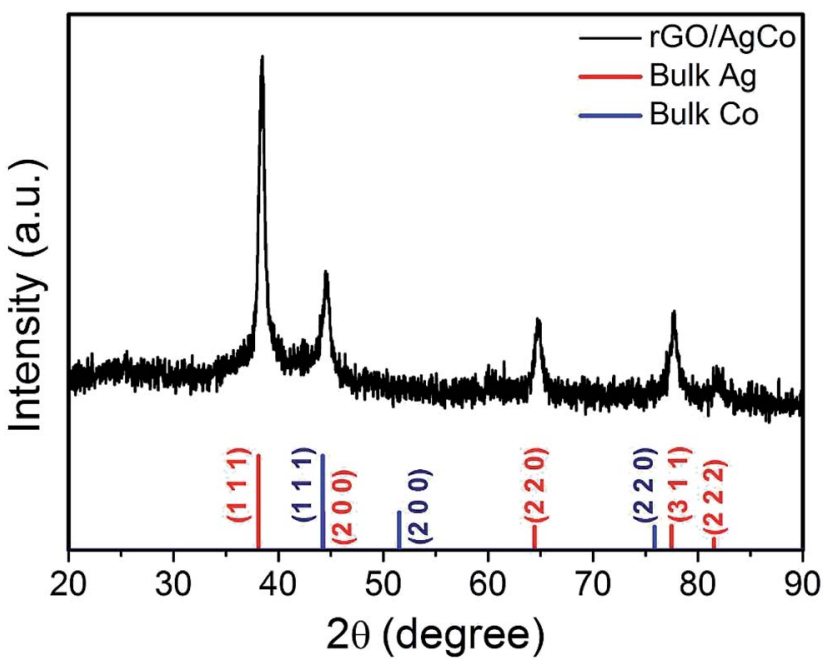

Fig. 3 XRD pattern of the synthesized $\mathrm{rGO} / \mathrm{AgCo}$ composite nanosheets. The XRD patterns of bulk Ag in red (JCPDS 04-0783) and Co in blue (JCPDS 15-0806) has also shown at the bottom of the image. 

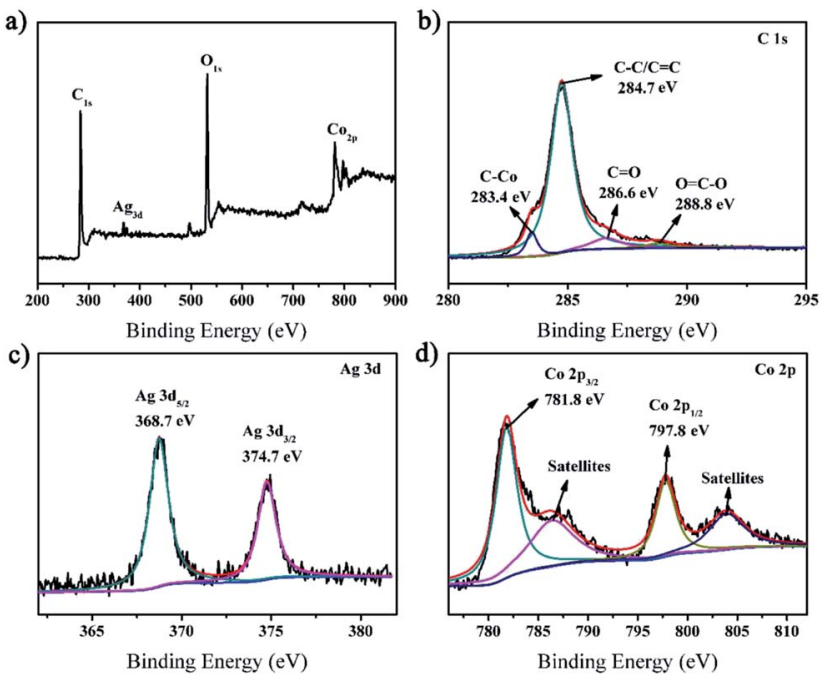

Fig. 4 XPS spectra of the synthesized $\mathrm{rGO} / \mathrm{AgCo}$ composite nanosheets. (a) Survey spectrum; (b) C 1s; (c) Ag 3d; (d) Co 2p.

From Fig. 4d, it can be observed that four characteristic peaks appeared in the Co $2 \mathrm{p}$ spectrum. The first two peaks at about 781.8 and $797.8 \mathrm{eV}$ are related to Co $2 \mathrm{p}_{3 / 2}$ and Co $2 \mathrm{p}_{1 / 2}$, and the other two peaks with higher binding energies at around 786.4 and $804.0 \mathrm{eV}$ are assigned to the shake-up satellites. ${ }^{29}$

The as-prepared rGO/AgCo composite nanosheets has been proven to be efficient catalyst toward the reduction of $\mathrm{MB}$ in the presence of $\mathrm{NaBH}_{4}$. The catalytic process can be monitored by time dependent UV-vis spectroscopy. As shown in Fig. S1a, $\uparrow$ the aqueous solution of $\mathrm{MB}$ is blue in color and exhibits a strong absorption at $665 \mathrm{~nm}$. After the addition of $\mathrm{NaBH}_{4}$, the absorption peak decreases obviously and almost disappears in $8 \mathrm{~min}$, indicating the completely reduction of $\mathrm{MB}$. The reduction of $\mathrm{MB}$ by $\mathrm{NaBH}_{4}$ in the presence of $\mathrm{rGO} / \mathrm{AgCo}$ composite nanosheets can be explained using Langmuir-Hinshelwood mechanism. The $\mathrm{BH}_{4}{ }^{-}$from $\mathrm{NaBH}_{4}$ and $\mathrm{MB}$ are simultaneously adsorbed on the surface of $\mathrm{rGO} / \mathrm{AgCo}$ composite nanosheets. After adsorption, the $\mathrm{BH}_{4}{ }^{-}$ions transfer the electrons to $\mathrm{MB}$ through $\mathrm{rGO} / \mathrm{AgCo}$ composite nanosheets. Herein, $\mathrm{rGO} / \mathrm{AgCo}$ composite nanosheets act as electron transfer mediator, which reduce the energy barrier between the reactant and product. We have also compared the catalytic activity of the asprepared $\mathrm{rGO} / \mathrm{AgCo}$ composite nanosheets with that of $\mathrm{rGO} / \mathrm{Ag}$ and $\mathrm{rGO} / \mathrm{Co}$ composite nanosheets. It was found that the $\mathrm{rGO} /$ AgCo composite nanosheets possessed a higher catalytic activity for the reduction of $\mathrm{MB}$ by $\mathrm{NaBH}_{4}$ than individual $\mathrm{rGO}$ / $\mathrm{Ag}$ and $\mathrm{rGO} / \mathrm{Co}$ composite nanosheets. In addition, we have also investigated the influence of $\mathrm{Ag} / \mathrm{Co}$ molar ratio to the catalytic reduction of $\mathrm{MB}$ in the presence of $\mathrm{NaBH}_{4}$. It is found that the catalytic activity of $\mathrm{rGO} / \mathrm{AgCo}$ is higher than that of $\mathrm{rGO} / \mathrm{Ag}_{1} \mathrm{Co}_{3}$ and $\mathrm{rGO} / \mathrm{Ag}_{3} \mathrm{Co}_{1}$. The reaction kinetics toward the reduction of MB has also been studied. Fig. 5a showed the linear relationship between $\ln \left(I_{t} / I_{0}\right)$ and the reaction time for the catalytic reduction of $\mathrm{MB}$ by $\mathrm{rGO} / \mathrm{AgCo}$ composite nanosheets, where in $I_{t}$ and $I_{0}$ stand for the absorption intensities at $665 \mathrm{~nm}$ at time $t$ and 0 , respectively. Form Fig. $5 \mathrm{a}$, it can be clearly observed that
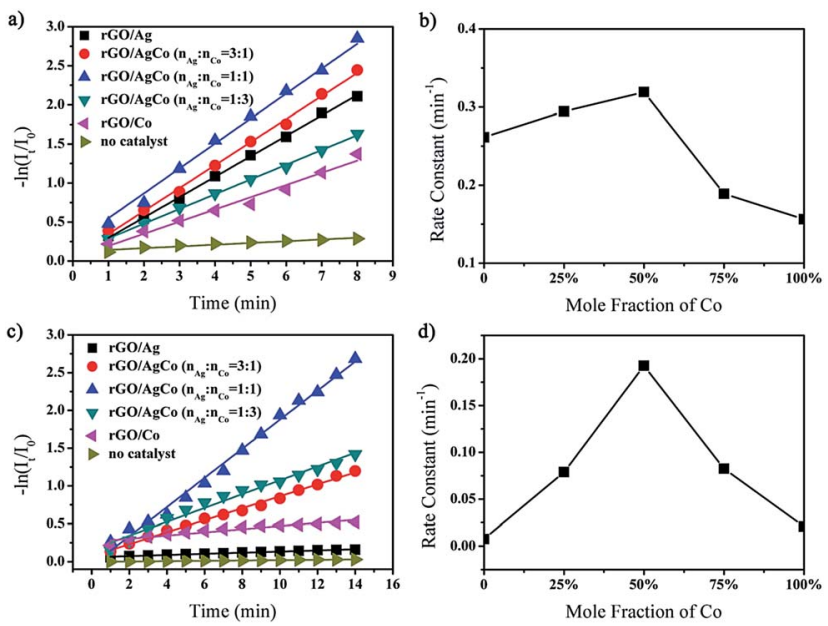

Fig. 5 (a) Plots of $\ln \left(I_{t} / I_{0}\right)$ versus time for rate constant calculation of the reduction of $\mathrm{MB}$ by $\mathrm{NaBH}_{4}$ in the presence of as-synthesized samples with different $\mathrm{Ag} / \mathrm{Co}$ molar ratio and blank control; (b) the relationship between the rate constant and the mole fraction of Co for the reduction of $\mathrm{MB}$ by $\mathrm{NaBH}_{4}$; (c) plots of $\ln \left(I_{t} / I_{0}\right)$ versus time for rate constant calculation of the degradation of MB under UV light in the presence of as-synthesized samples with different $\mathrm{Ag} / \mathrm{Co}$ molar ratio and blank control; (d) the relationship between the rate constant and the mole fraction of Co for the photodegradation of MB under UV light.

MB molecules are almost not reduced by only $\mathrm{NaBH}_{4}$ in the absence of $\mathrm{rGO} / \mathrm{AgCo}$ composite nanosheets. Based on the rate law of the fitting equation of $\ln \left(I_{t} / I_{0}\right)=0.22994+0.31906 t$, the rate constant can be calculated to be about $0.32 \mathrm{~min}^{-1}$ for $\mathrm{rGO} /$ AgCo composite nanosheets as catalyst, which was higher than that of $\mathrm{rGO} / \mathrm{Ag}\left(0.26 \mathrm{~min}^{-1}\right), \mathrm{rGO} / \mathrm{Co}\left(0.15 \mathrm{~min}^{-1}\right), \mathrm{rGO} / \mathrm{Ag}_{3} \mathrm{Co}_{1}$ $\left(0.29 \mathrm{~min}^{-1}\right)$, and $\mathrm{rGO} / \mathrm{Ag}_{1} \mathrm{Co}_{3}\left(0.19 \mathrm{~min}^{-1}\right)$ as catalysts, respectively (Fig. 5b). This result indicates that $\mathrm{rGO} / \mathrm{AgCo}$ composite nanosheets with 1:1 Ag/Co molar ratio possess the highest catalytic activity for reduction of $\mathrm{MB}$ by $\mathrm{NaBH}_{4}$. The as-prepared $\mathrm{rGO} / \mathrm{AgCo}$ composite nanosheets are also good photocatalyst for the degradation of $\mathrm{MB}$ under UV light. As shown in Fig. 5c, the individual $\mathrm{rGO} / \mathrm{Ag}$ composite nanosheets almost did not show photocatalytic activity toward the degradation of $\mathrm{MB}$ under UV light, indicating that $\mathrm{rGO} / \mathrm{Ag}$ is inert toward the photocatalytic degradation of $\mathrm{MB}$. On the other hand, rGO/Co composite nanosheets exhibit much lower catalytic activity than that of $\mathrm{rGO} / \mathrm{AgCo}$ composite nanosheets. From Fig. 5d, it is found that the rate constant for the catalytic degradation of $\mathrm{MB}$ by $\mathrm{rGO} / \mathrm{AgCo}$ composite nanosheets under UV light is calculated to be about $0.19 \mathrm{~min}^{-1}$, which is much higher than those of $\mathrm{rGO} / \mathrm{Ag}\left(0.01 \mathrm{~min}^{-1}\right), \mathrm{rGO} / \mathrm{Co}\left(0.02 \mathrm{~min}^{-1}\right)$, $\mathrm{rGO} / \mathrm{Ag}_{3} \mathrm{Co}_{1}\left(0.08 \mathrm{~min}^{-1}\right)$, and $\mathrm{rGO} / \mathrm{Ag}_{1} \mathrm{Co}_{3}\left(0.09 \mathrm{~min}^{-1}\right)$ as the photocatalysts. Generally, the catalytic and photocatalytic activities are related to the surface area of the catalysts. Thus we have estimated the surface areas of the prepared catalysts. As shown in Fig. S2, $\uparrow$ the Brunauer-Emmett-Teller (BET) surface area of $\mathrm{rGO} / \mathrm{AgCo}$ composite nanosheets is reckoned to be about $99.4 \mathrm{~m}^{2} \mathrm{~g}^{-1}$, which is higher than that of $\mathrm{rGO} / \mathrm{Ag}\left(67.3 \mathrm{~m}^{2} \mathrm{~g}^{-1}\right)$ and $\mathrm{rGO} / \mathrm{Ag}_{3} \mathrm{Co}_{1}$ composite nanosheets $\left(78.9 \mathrm{~m}^{2} \mathrm{~g}^{-1}\right)$, but lower than that of $\mathrm{rGO} / \mathrm{Co}\left(101.9 \mathrm{~m}^{2} \mathrm{~g}^{-1}\right)$ and $\mathrm{rGO} / \mathrm{Ag}_{1} \mathrm{Co}_{3}$ composite 
nanosheets $\left(177.6 \mathrm{~m}^{2} \mathrm{~g}^{-1}\right)$. Therefore, the enhanced catalytic and photocatalytic activity of $\mathrm{rGO} / \mathrm{AgCo}$ composite nanosheets should also be attributed to the synergistic effect between rGO and AgCo alloys. On the one hand, the rGO nanosheets with a high conductivity facilitate a fast electron transfer between substrate molecules and AgCo alloy nanoparticles. In addition, the $\mathrm{rGO}$ nanosheets also prevent the aggregation of AgCo alloy nanoparticles. On the other hand, electron transfer from Co to $\mathrm{Ag}$ will take place due to their different electronegativities, resulting in a partial charge separation on the CoAg alloy surface. The prepared $\mathrm{rGO} / \mathrm{AgCo}$ composite nanosheets display a balanced $\mathrm{Ag} / \mathrm{Co}$ ratio and generate the best charge separation, generating highest catalytic and photocatalytic activities.

The as-prepared $\mathrm{rGO} / \mathrm{AgCo}$ composite nanosheets are not only excellent catalyst and photocatalyst for the reduction and degradation of MB, but also efficient SERS substrate for the detection of various target molecules. In this work, we have evaluated the SERS properties of $\mathrm{rGO} / \mathrm{AgCo}$ composite nanosheets using PATP and MBA as model probes. Fig. 6a showed the SERS spectra of PATP molecules with different concentrations from $10^{-3}$ to $10^{-9} \mathrm{M}$ on the surface of $\mathrm{rGO} / \mathrm{AgCo}$ composite nanosheets. It can be clearly seen that very strong Raman bands of PATP molecules appear in the SERS spectrum when the concentration of PATP is $10^{-3} \mathrm{M}$. The characteristic peaks at 1576 and $1072 \mathrm{~cm}^{-1}$ are attributed to the $\mathrm{C}-\mathrm{C}$ and $\mathrm{C}-\mathrm{S}$
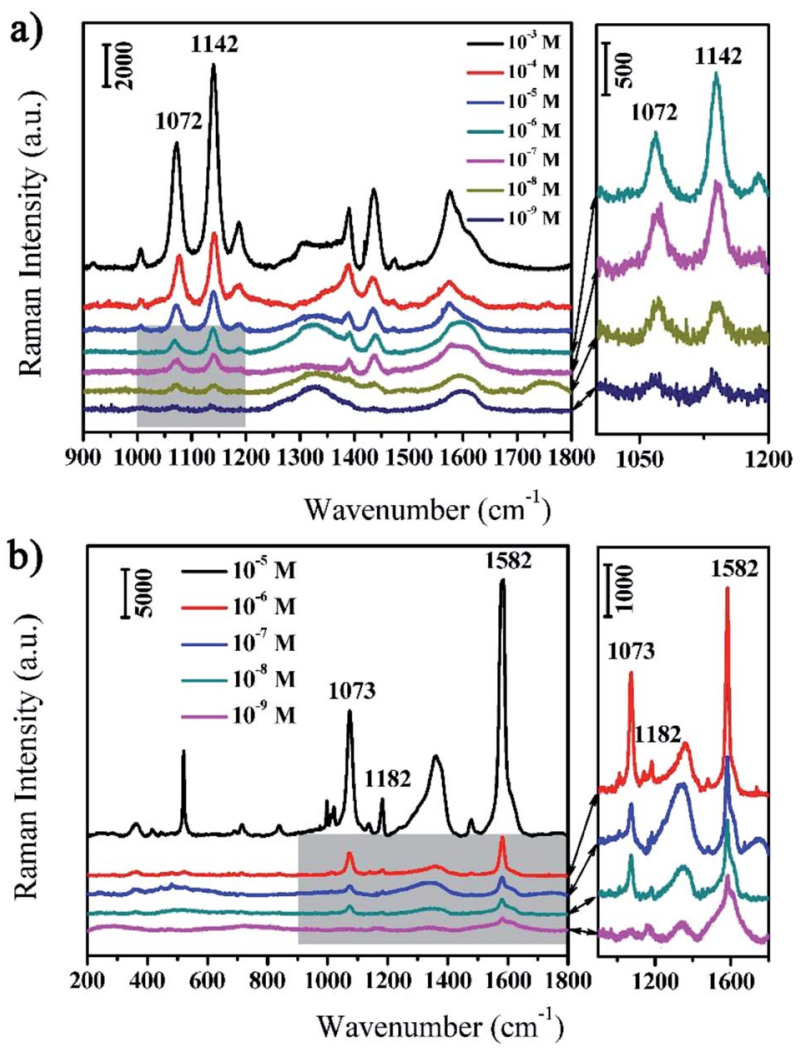

Fig. 6 (a) SERS spectra of PATP molecules with different concentrations $\left(10^{-3}-10^{-9} \mathrm{M}\right)$ on the surface of $\mathrm{rGO} / \mathrm{AgCo}$ composite nanosheets; (b) SERS spectra of MBA molecules with different concentrations $\left(10^{-5}-10^{-9} \mathrm{M}\right)$ on the surface of $\mathrm{rGO} / \mathrm{AgCo}$ composite nanosheets. stretching mode of PATP molecules, which are related to the $\mathrm{a}_{1}$ modes of PATP (Fig. 6a). In addition, some other typical bands at $1435,1389,1187,1142 \mathrm{~cm}^{-1}$ are also clearly observed in the SERS spectrum, which can be assigned to $b_{2}$ symmetry of PATP molecules. The strong resonance enhancement of these bands are due to the charge transfer process. ${ }^{30}$ It is also found that the intensities of the typical $a_{1}$ and $b_{2}$ bands of PATP molecules decrease with the reducing of their concentrations. However, the typical bands of PATP molecules were still distinguished when the concentration of PATP molecules decreased to $10^{-9} \mathrm{M}$, suggesting the high SERS sensitivity of $\mathrm{rGO} / \mathrm{AgCo}$ composite nanosheets. On the other hand, Fig. $6 \mathrm{~b}$ showed the SERS spectra of MBA molecules with different concentrations from $10^{-5}$ to $10^{-9} \mathrm{M}$ on the surface of $\mathrm{rGO} / \mathrm{AgCo}$ composite nanosheets. All Raman peaks were characteristic SERS signals of MBA molecules. For instance, the strong band at $1582 \mathrm{~cm}^{-1}$ is assigned to the aromatic $\nu(\mathrm{C}-\mathrm{C})$ mode, and the typical peak at $1073 \mathrm{~cm}^{-1}$ is ascribed to the in-plane ring breathing mode coupled with $\nu(\mathrm{C}-\mathrm{S})$. The relative weak band at $1182 \mathrm{~cm}^{-1}$ is attributed to the $\mathrm{C}-\mathrm{H}$ deformation mode. ${ }^{31,32}$ Similarly, the intensities of the characteristic bands of MBA molecules decrease with the decreasing of their concentrations, however, the typical bands at $1582 \mathrm{~cm}^{-1}$ are still observed when the concentration of MBA decreased to $10^{-9} \mathrm{M}$. These results demonstrated that the as-prepared $\mathrm{rGO} / \mathrm{AgCo}$ composite nanosheets are efficient SERS substrates. Furthermore, we have also investigated the SERS sensitivity of the $\mathrm{rGO} / \mathrm{AgCo}$ composite nanosheets that synthesized in the solution with different $\mathrm{pH}$ values. As shown in Fig. S3a, $\uparrow$ the $\mathrm{rGO} / \mathrm{AgCo}$ composite nanosheets that synthesized in a solution with $\mathrm{pH}$ value of 9.0 show the highest SERS intensity compared to other substrates using PATP molecules as probes. The similar results have also been obtained by using MBA molecules as probes. Therefore, the $\mathrm{pH}$ $=9.0$ is an optimal condition for the preparation of $\mathrm{rGO} / \mathrm{AgCo}$ composite nanosheets as SERS substrates.

Owing to the excellent catalytic activities and efficient SERS properties, the as-prepared $\mathrm{rGO} / \mathrm{AgCo}$ composite nanosheets can be used as SERS substrate for in situ monitoring the catalytic reaction process and determine the reaction kinetics of the reduction of $\mathrm{MB}$ by $\mathrm{NaBH}_{4}$. Fig. 7a shows the SERS spectra of MB molecules on the surface of $\mathrm{rGO} / \mathrm{AgCo}$ composite nanosheets in the presence of $\mathrm{NaBH}_{4}$ at different time intervals. It was clearly observed that three typical peaks at 1623,1475 , and $1400 \mathrm{~cm}^{-1}$
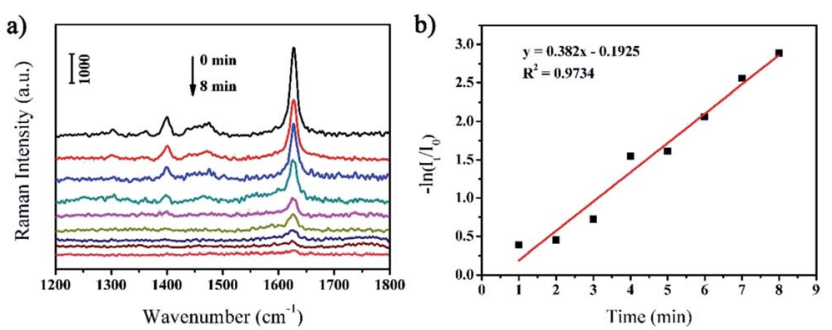

Fig. 7 (a) The change of SERS spectra for the catalytic reduction of MB by $\mathrm{NaBH}_{4}$ on the surface of $\mathrm{rGO} / \mathrm{AgCo}$ composite nanosheets. (b) The curve of the linear relationship between $\ln \left(I_{t} / I_{0}\right)$ and the reaction time according to the bands at $1623 \mathrm{~cm}^{-1}$. 
appeared in the SERS spectrum before the addition of $\mathrm{NaBH}_{4}$ in the system. These three peaks are ascribed to $\mathrm{C}-\mathrm{C}$ ring stretching, $\mathrm{C}-\mathrm{N}$ stretching and $\mathrm{N}-\mathrm{C}-\mathrm{H}$ in-plane bending vibrations, respectively. ${ }^{33}$ However, the SERS intensity of the three peaks of MB gradually decreases with increasing time after the addition of $\mathrm{NaBH}_{4}$. And these peaks almost disappear in $8 \mathrm{~min}$, demonstrating completely reduction of $\mathrm{MB}$ on the surface of $\mathrm{rGO} / \mathrm{AgCo}$ composite nanosheets. The catalytic reduction of $\mathrm{MB}$ by $\mathrm{rGO} /$ AgCo composite nanosheets can be indexed by a LangmuirHinshelwood model. Fig. $7 \mathrm{~b}$ shows the linear relationship between $\ln \left(I_{t} / I_{0}\right)$ and the reaction time toward the catalytic reduction of $\mathrm{MB}$ by $\mathrm{rGO} / \mathrm{AgCo}$ composite nanosheets, wherein $I_{t}$ and $I_{0}$ stand for the SERS intensities at $1623 \mathrm{~cm}^{-1}$ at time $t$ and 0 , respectively. Then a fitting equation of $\ln \left(I_{t} / I_{0}\right)=-0.1925+0.382 t$ was obtained, which showed the pseudo-first order reaction. The rate constant of the catalytic reaction can be calculated to be about $0.382 \mathrm{~min}^{-1}$. In addition, the rate constant at the beginning of the catalytic reaction has also been studied. As shown in Fig. $\mathrm{S} 4 \mathrm{a}, \dagger$ the rate constant is about $0.0062 \mathrm{~s}^{-1}$, which is much lower than the rate constant calculated from the whole reaction, indicating an induction period for the catalytic reaction.

Similar with the in situ monitoring the catalytic degradation of $\mathrm{MB}$ by $\mathrm{NaBH}_{4}$, the as-prepared $\mathrm{rGO} / \mathrm{AgCo}$ composite nanosheets can also be used as SERS substrate for monitoring of the photocatalytic degradation of MB under UV light. Fig. 8a shows the SERS spectra of MB molecules on the surface of $\mathrm{rGO} / \mathrm{AgCo}$ composite nanosheets under UV light at different time intervals. Similar with the Fig. 7a, it is clearly seen that the intensity of the characteristic peaks of MB molecules gradually decreased with increasing time under UV light, and these peaks almost disappeared in $13 \mathrm{~min}$. The linear relationship between $\ln \left(I_{t} / I_{0}\right)$ and the reaction time toward the photocatalytic degradation of MB by rGO/AgCo composite nanosheets under UV light has also been shown in Fig. 8b. The rate law can be expressed as a fitting equation of $\ln \left(I_{t} / I_{0}\right)=-0.4304+0.2115 t$. Based on this equation, the photocatalytic degradation of MB follows a pseudofirst order reaction. And the rate constant of the photocatalytic reaction can be calculated to be about $0.2115 \mathrm{~min}^{-1}$. The rate constant at the beginning of the photocatalytic reaction has also been studied. As shown in Fig. $\mathrm{S} 4 \mathrm{~b}, \dagger$ the rate constant is about $0.0007 \mathrm{~s}^{-1}$, which is much lower than the rate constant calculated from the whole reaction, demonstrating an induction period for the photocatalytic reaction.
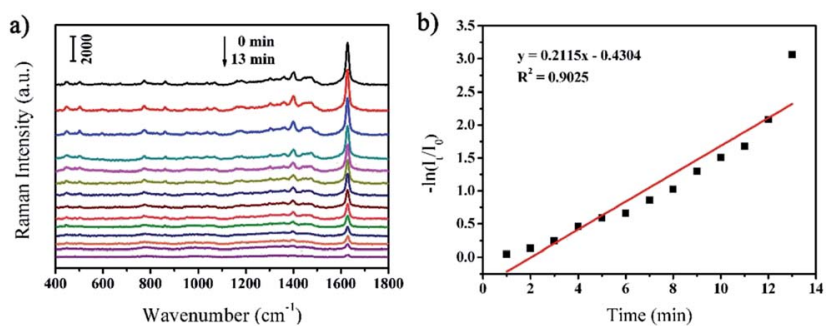

Fig. 8 (a) The change of SERS spectra for the catalytic degradation of $\mathrm{MB}$ under UV light on the surface of $\mathrm{rGO} / \mathrm{AgCo}$ composite nanosheets. (b) The curve of the linear relationship between $\ln \left(I_{t} / I_{0}\right)$ and the reaction time according to the bands at $1623 \mathrm{~cm}^{-1}$.
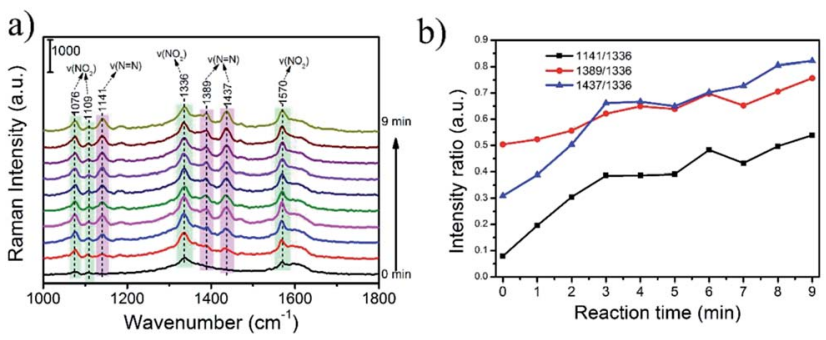

Fig. 9 (a) Time-dependent SERS spectra of plasmon-enhanced driven catalytic reaction of PNTP dimerizing into DMAB on the surface of rGO/AgCo composite nanosheets; (b) the curve of the relationship between relative SERS intensity and reaction time.

In this work, we have also performed the prepared $\mathrm{rGO} / \mathrm{AgCo}$ composite nanosheets as SERS substrate for in situ monitoring of the plasmon-driven catalytic reaction of PNTP dimerizing into DMAB. As shown in Fig. 9a and b, an excellent SERS activities of PNTP has been observed on the surface of the $\mathrm{rGO} /$ AgCo composite nanosheets. At the beginning SERS measurement, the characteristic peaks at 1336 and $1570 \mathrm{~cm}^{-1}$ are clearly observed, which are attributed to the $-\mathrm{NO}_{2}$ stretching mode of PNTP. ${ }^{34}$ After continuous laser excitation, some new bands at 1141,1389 and $1437 \mathrm{~cm}^{-1}$ gradually emerged. And the intensity of these peaks increase with the increasing reaction time. These three typical peaks are ascribed to $\mathrm{C}-\mathrm{N}$ symmetric stretching, $\mathrm{N}=\mathrm{N}$ stretching, and $\mathrm{C}-\mathrm{H}$ in-plane bending modes of DMAB, respectively. This result suggests that PNTP has been dimerized into DMAB due to the plasmon driven catalytic reaction. However, the intensities of the peaks at 1336 and $1570 \mathrm{~cm}^{-1}$ did not obviously decrease, indicating that only a part of PNTP molecules were dimerized into DMAB, which is similar with the previous reports. ${ }^{34,35}$ We proposed a possible mechanism for the dimerization of PNTP into DMAB (Fig. S5 $†$ ). The dimerization process requires $4 \mathrm{e}^{-}$, which can be produced from hot electrons arising from surface plasmon. ${ }^{35-39}$ Therefore, the conversion of PNTP into DMAB can be attributed to the reduction process by the hot electrons that are generated by surface plasmon decay on the surface of $\mathrm{rGO} / \mathrm{AgCo}$ composite nanosheets. The hot electrons generated by plasmon decay possess high kinetic energy, which can drive the surface-catalyzed reaction.

\section{Conclusions}

In summary, we have demonstrated a facile co-reduction approach to prepare $\mathrm{rGO} / \mathrm{AgCo}$ composite nanosheets. The prepared AgCo nanoparticles are uniformly distributed on the surface of rGO nanosheets. The synthesized rGO/AgCo composite nanosheets have been employed as catalyst and photocatalyst toward the reduction and degradation of $\mathrm{MB}$ and show superior catalytic and photocatalytic activities over individual $\mathrm{rGO} / \mathrm{Ag}$ and $\mathrm{rGO} / \mathrm{Co}$ composite nanosheets. The $\mathrm{rGO} /$ AgCo composite nanosheets are also used as efficient SERS substrate for monitoring the catalytic and photocatalytic reaction toward the reduction and degradation of $\mathrm{MB}$, and the plasmon-driven of PNTP dimerizing into DMAB. It is 
anticipated that this study offers a facile approach for the fabrication of multi-functional nanocomposites for a large variety of applications in the fields of catalysts, biosensing, and environmental science and technology.

\section{Conflicts of interest}

There are no conflicts to declare.

\section{Acknowledgements}

This work was supported by the research grants from the National Natural Science Foundation of China (21473068, 21327803).

\section{References}

1 Y. Xia, Y. Xiong, B. Lim and S. E. Skrabalak, Angew. Chem., Int. Ed., 2009, 48, 60-103.

2 Z. Quan, Y. Wang and J. Fang, Acc. Chem. Res., 2013, 46, 191202.

3 S. Gong and W. Cheng, Adv. Electron. Mater., 2017, 3, 1600314.

4 T. A. Taton, C. A. Mirkin and R. L. Letsinger, Science, 2000, 289, 1757-1760.

5 Y. W. Jun, J. W. Seo and A. Cheon, Acc. Chem. Res., 2008, 41, 179-189.

6 K. D. Gilroy, A. Ruditskiy, H. C. Peng, D. Qin and Y. N. Xia, Chem. Rev., 2016, 116, 10414-10472.

7 B. Lim, M. Jiang, P. H. C. Camargo, E. C. Cho, J. Tao, X. Lu, Y. Zhu and Y. Xia, Science, 2009, 324, 1302-1305.

8 L. Ai, X. Liu and J. Jiang, J. Alloys Compd., 2015, 625, 164-170.

9 Z. Qu, D. Chen, Y. Sun and Y. Wang, Appl. Catal., A, 2014, 487, 100-109.

10 Y. Tong, X. Lu, W. Sun, G. Nie, L. Yang and C. Wang, J. Power Sources, 2014, 261, 221-226.

11 Y. Cheng, Y. Fan, Y. Pei and M. Qiao, Catal. Sci. Technol., 2015, 5, 3903-3916.

12 Q. J. Xiang, J. G. Yu and M. Jaroniec, Chem. Soc. Rev., 2012, 41, 782-796.

13 E. Antolini, Appl. Catal., B, 2012, 123-124, 52-68.

14 J. Lv, A. Wang, X. Ma, R. Xiang, J. Chen and J. Feng, J. Mater. Chem. A, 2015, 3, 290-295.

15 R. Dhanda and M. Kidwai, J. Mater. Chem. A, 2015, 3, 1956319574.

16 L. Yang, J. Su, X. Meng, W. Luo and G. Cheng, J. Mater. Chem. A, 2013, 1, 10016-10023.

17 X. Ling, L. M. Xie, Y. Fang, H. Xu, H. L. Zhang, J. Kong, M. S. Dresselhaus, J. Zhang and Z. F. Liu, Nano Lett., 2010, 10, 553-561.
18 W. G. Xu, N. N. Mao and J. Zhang, Small, 2013, 9, 1206-1224. 19 Z. Zhang, F. G. Xu, W. S. Yang, M. Y. Gao, X. D. Wang, B. L. Zhang and J. L. Tang, Chem. Commun., 2011, 47, 6440-6442.

20 J. Lee, S. Shim, B. Kim and H. S. Shin, Chem.-Eur. J., 2011, 17, 2381-2387.

21 G. Lu, H. Li, C. Liusman, Z. Y. Yin, S. X. Wu and H. Zhang, Chem. Sci., 2011, 2, 1817-1821.

22 C. Y. Wen, F. Liao, S. S. Liu, Y. Zhao, Z. H. Kang, X. L. Zhang and M. W. Shao, Chem. Commun., 2013, 49, 3049-3051.

23 Y. Guo, H. Wang, X. W. Ma, J. Jin, W. Ji, X. Wang, W. Song, B. Zhao and C. Y. He, ACS Appl. Mater. Interfaces, 2017, 9, 19074-19081.

24 W. S. Hummers and R. E. Offeman, J. Am. Chem. Soc., 1958, 80, 1339.

25 E. Jin, X. F. Lu, L. L. Cui, D. M. Chao and C. Wang, Electrochim. Acta, 2010, 55, 7230-7234.

26 X. Lu, L. Yang, X. Bian, D. Chao and C. Wang, Part. Part. Syst. Charact., 2014, 31, 245-251.

27 Z. Ji, X. Shen, G. Zhu, H. Zhou and A. Yuan, J. Mater. Chem., 2012, 22, 3471-3477.

28 W. Song, W. Ji, S. Vantasin, I. Tanabe, B. Zhao and Y. Ozaki, J. Mater. Chem. A, 2015, 3, 13556-13562.

29 Z. Z. Yang, Z. Zhang, Y. Z. Jiang, M. Q. Chi, G. D. Nie, X. F. Lu and C. Wang, RSC Adv., 2016, 6, 33636-33642.

30 Z. Mao, W. Song, X. X. Xue, W. Ji, Z. S. Li, L. Chen, H. J. Mao, H. M. Lv, X. Wang, J. R. Lombardi and B. Zhao, J. Phys. Chem. C, 2012, 116, 14701-14710.

31 Y. Wang, W. Ji, H. M. Sui, Y. Kitahama, W. D. Ruan, Y. Ozaki and B. Zhao, J. Phys. Chem. C, 2014, 118, 10191-10197.

32 M. D. Gong, X. Jiang, J. Du, X. L. Li, X. X. Han, L. B. Yang and B. Zhao, RSC Adv., 2015, 5, 80269-80275.

33 S. Dutta Roy, M. Ghosh and J. Chowdhury, J. Raman Spectrosc., 2015, 46, 451-461.

34 J. Jin, S. J. Zhu, Y. B. Song, H. Y. Zhao, Z. Zhang, Y. Guo, J. B. Li, W. Song, B. Yang and B. Zhao, ACS Appl. Mater. Interfaces, 2016, 8, 27956-27965.

35 P. Li, B. B. Ma, L. B. Yang and J. H. Liu, Chem. Commun., 2015, 51, 11394-11397.

36 M. W. Knight, H. Sobhani, P. Nordlander and N. J. Halas, Science, 2011, 332, 702-704.

37 B. Dong, Y. Fang, X. Chen, H. Xu and M. Sun, Langmuir, 2011, 27, 10677-10682.

38 M. Sun and H. Xu, Small, 2012, 8, 2777-2786.

39 W. Song, C. J. Querebillo, R. Götz, S. Katz, U. Kuhlmann, U. Gernert, I. M. Weidinger and P. Hildebrandt, Nanoscale, 2017, 9, 8380-8387. 